\title{
Influence of Hygrothermal Aging on Poisson's Ratio of Thin Injection-Molded Short Glass Fiber-Reinforced PA6
}

\author{
Thomas Illing ${ }^{1, *}$, Heinrich Gotzig ${ }^{1}$, Marcus Schoßig ${ }^{2}$, Christian Bierögel ${ }^{2,3}$ and \\ Wolfgang Grellmann ${ }^{2,3}$ \\ 1 Valeo Schalter und Sensoren GmbH, Bietigheim-Bissingen, Bissingen D-74321, Germany; \\ heinrich.gotzig@valeo.com \\ 2 Polymer Service GmbH Merseburg, Merseburg D-06217, Germany; \\ marcus.schossig@psm-merseburg.de (M.S.); christian.bieroegel@psm-merseburg.de (C.B.); \\ wolfgang.grellmann@iw.uni-halle.de (W.G.) \\ 3 Center of Engineering Sciences, Martin-Luther-University Halle-Wittenberg, Halle (Saale) D-06099, Germany \\ * Correspondence: thomas.illing@valeo.com; Tel.: +49-7142-916-1027
}

Academic Editor: Edith Maeder

Received: 3 February 2016; Accepted: 9 May 2016; Published: 17 May 2016

\begin{abstract}
The hygrothermal aging of short glass fiber-reinforced polyamide 6 materials (PA6 GF) represents a major problem, especially in thin-walled components, such as in the automotive sector. In this study, therefore, the thickness and the glass fiber content of PA6 GF materials were varied and the materials were exposed to hygrothermal aging. The temperature and relative humidity were selected in the range from $-40{ }^{\circ} \mathrm{C}$ up to $85^{\circ} \mathrm{C}$, and from $10 \%$ up to $85 \%$ relative humidity (RH). In the dry-as-molded state, the determined Poisson's ratio of the PA6 GF materials was correlated with the fiber orientation based on computer tomography (MicroCT) data and shows a linear dependence with respect to the fiber orientation along and transverse to the flow direction of the injection molding process. With hygrothermal aging, the value of Poisson's ratio increases in the flow direction in the same way as it decreases perpendicular to the flow direction due to water absorption.
\end{abstract}

Keywords: polyamide 6; glass fiber; hygrothermal aging; poisson's ratio

\section{Introduction}

The short glass fiber-reinforced polyamide 6 materials (PA6 GF) have been successfully used for many decades in the automotive industry, especially for components in exterior and interior areas. The advantageous combination of mechanical and thermal properties, together with a convenient production process that utilizes injection molding, allows a wide operational range and variable shaping. Due to product safety requirements in the automotive industry, components are exposed to hygrothermal stress during the development phase. However, the current trends towards lighter-weight components and less material consumption are leading to thinner wall dimensions in automotive components. At the same time, demands for accuracy, tolerance and aging stability are increasing strongly. This study aims to contribute to a broader understanding of the mechanical properties like Poisson's ratio of short glass fiber-reinforced polyamide 6 materials as a function of glass fiber orientation and at hygrothermal aging conditions.

The mechanical properties of glass fiber-reinforced polyamide materials, in general, depend on glass fiber content, glass fiber diameter and glass fiber length (aspect ratio), as well as the glass fiber orientation [1-3]. The glass fiber orientation is generated mainly by the injection molding process and can be determined visually or by X-ray diffraction analysis $[4,5]$. The glass fiber orientations can be represented by the tensor second stage $\boldsymbol{T}_{\mathrm{FOD}}$ as shown in Equation (1) based on the angles $\Phi$ and $\Theta$ 
(from polar coordinate system, see Figure 1), which describes the average glass fiber orientation in a defined region in the Cartesian coordinate system according to Advani and Tucker as well as Bay and Tucker [6-8]. Equation (1) is based on the probability distribution function of fiber orientation state at a point in space by Advani and Tucker [8]. The indices used in Equation (1) ( $x x, y y$ and $z z)$ are the principal axes in the coordinate system based on the flow direction of the injection molding process, where $x x$ stands for the flow or longitudinal direction, $y y$ stands for in-plane direction transverse to the flow direction and $z z$ stands for out-of-plane direction. Based on the normalization of the tensor $T_{\mathrm{FOD}}$ it follows that $a_{x x}+a_{y y}+a_{z z}=1$. Furthermore, the number of components of the tensor can be reduced due to symmetry conditions from 9 to 6; the components $a_{x y}, a_{x z}$ and $a_{y z}$ are not considered due to negligible results [1].

$$
\boldsymbol{T}_{F O D}=\left[\begin{array}{lll}
a_{x x} & & \\
& a_{y y} & \\
& & a_{z z}
\end{array}\right]=\left[\begin{array}{ccc}
\sin ^{2} \Theta \cos ^{2} \Phi & & \\
& \sin ^{2} \Theta \sin ^{2} \Phi & \\
& & \cos ^{2} \Theta
\end{array}\right]
$$

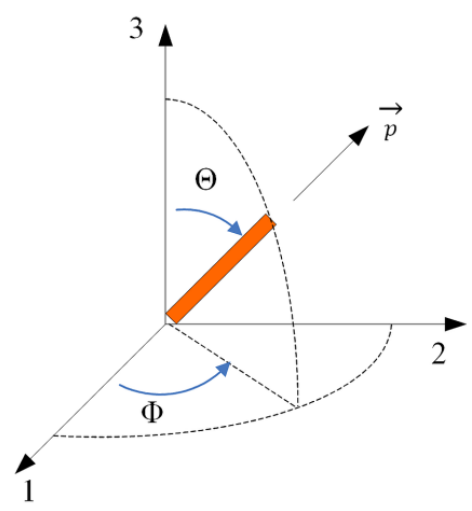

Figure 1. Representation of the solid angle of fiber orientation with respect to axis name according to Advani and Tucker; 1 to denote flow direction $x, 2$ to denote in-plane transverse to flow direction $y$ and 3 to denote thickness direction $z$ [8].

The Poisson's ratio $\mu$ describes the ratio of transverse strain $\varepsilon_{\mathrm{q}}$ to tensile strain $\varepsilon_{1}$ under uniaxial mechanical stress (see Equation (2)) and is given in some common standard publications as a material-specific constant $[9,10]$. A value of Poisson's ratio $\mu$ of 0.5 means incompressible material behavior and, thus, isotropy under uniaxial load [11].

$$
\mu=\left|\frac{\varepsilon_{q}}{\varepsilon_{l}}\right|
$$

As already mentioned by Kunz [11], Saechtling [12] and Bierögel and Grellmann [13], the Poisson's ratio in fiber-reinforced thermoplastic materials strongly depends on the fiber content. It is used in the design of mechanical components in FEM programs (Finite Element Methods) for the calculation of multi-axial stresses. Here, among other things, the change of the maximum shear stress criterion (von-Mises criterion) is often used [14]. Through a hygrothermal stress of PA6 GF materials, the absorption of water molecules by diffusion processes takes place as a function of relative humidity and is linked with a decrease of strength and stiffness due to the softening effect of the water inside the polymeric material. Otherwise the ductility and toughness of these materials strongly increase with the water content. This characteristic material behavior could be supported by chemical aging processes such as hydrolysis or oxidation (according to Kohan [15] and Becker and Brown [16], these processes start to impact PA6 from a temperature of about $80^{\circ} \mathrm{C}$ ), but could also be impeded by counteracting physical aging processes such as recrystallization. 
To support appropriate FEM simulations in the design of mechanical automotive mechanical parts the Poisson's ratio was therefore analyzed in a dry-as-molded state as well as at hygrothermal aging as a function of thickness, fiber content and glass fiber orientation. Thus far, no correlation of the Poisson's ratio $\mu$ with the glass fiber orientation in PA6 GF materials is known.

\section{Materials and Methods}

\subsection{Material and Manufacturing of Test Specimens}

In this work short glass fiber-reinforced polyamide 6 (PA6 GF) and unreinforced polyamide 6 (PA6) were studied. The materials were provided by BASF SE, Ludwigshafen, Germany. In Table 1, the tested materials and the respective glass fiber contents are listed.

Table 1. Investigated materials from BASF SE, Ludwigshafen (Germany) [17].

\begin{tabular}{cccc}
\hline Matrix material & $\begin{array}{c}\text { Glass fiber weight } \\
\text { content } \Psi(\mathbf{( - )}\end{array}$ & $\begin{array}{c}\text { Glass fiber volume } \\
\text { content } \varphi_{\mathbf{V}}(\mathbf{( - )}\end{array}$ & Material name \\
\hline PA6 & 0 & 0 & BASF Ultramid B3K \\
PA6 & 0.15 & 0.067 & BASF Ultramid B3EG3 \\
PA6 & 0.30 & 0.159 & BASF Ultramid B3EG6 \\
PA6 & 0.40 & 0.243 & BASF Ultramid B3G8 \\
\hline
\end{tabular}

For the investigations plates with the dimensions $185 \times 160 \mathrm{~mm}^{2}$ and a thickness of $1.5,3,4$ and $5 \mathrm{~mm}$ were prepared by injection molding. Six multipurpose test specimens of type 1A according ISO 3167 [18] were extracted from the plates by sawing and milling. This was done to evaluate the influence of the glass fiber orientation both along and transverse to the direction of injection molding. Figure 2 shows schematically the positions of the multipurpose test specimen in the injection molded plates; the film gate is indicated by a red arrow, and the fiber orientation by black dotted lines.

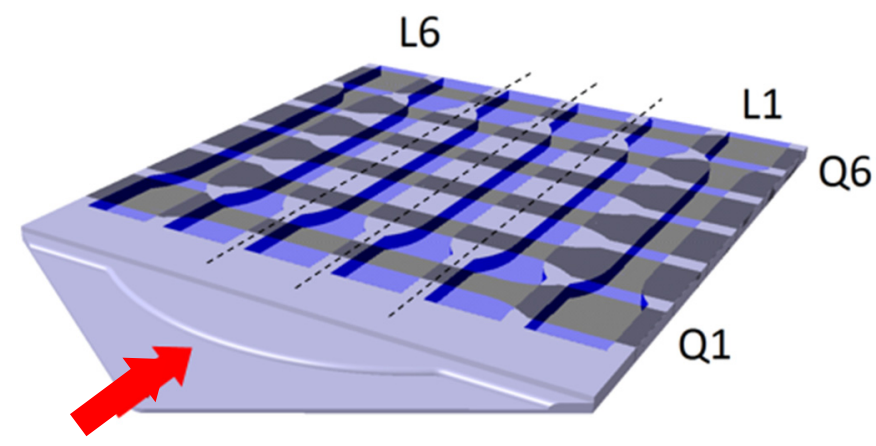

Figure 2. Schematic representation of the multipurpose test specimen, transverse and longitudinal to the fiber orientation in the plate.

\subsection{Hygrothermal Aging}

To generate an artificial aging of the semi-crystalline polymer several climate storages of each $1000 \mathrm{~h}$ with different temperatures and moisture contents were performed to assess the influence on the properties of the PA6 GF materials. The selected parameters for the climate conditions are listed together with the corresponding standards in Table 2.

At defined time intervals of $24 \mathrm{~h}, 48 \mathrm{~h}, 96 \mathrm{~h}, 480 \mathrm{~h}$, and $1000 \mathrm{~h}$, test specimens were taken out off the climate chamber to determine the change of mechanical properties. 
Table 2. Parameters of climate conditions and referenced standards.

\begin{tabular}{ccl}
\hline Temperature $\vartheta\left({ }^{\circ} \mathbf{C}\right)$ & $\begin{array}{c}\text { Relative humidity } \varphi_{\mathbf{R H}} \\
(\mathbf{\%} \mathbf{R H})\end{array}$ & \multicolumn{1}{c}{ Referenced standard } \\
\hline 85 & 10 & $\begin{array}{l}\text { IEC 60068-2-2: Environmental testing-Part 2-2: } \\
\text { Tests-Test B: Dry heat [19] }\end{array}$ \\
\hline 85 & 85 & $\begin{array}{l}\text { IEC 60068-2-78: Environmental testing-Part 2-78: } \\
\text { Tests-Test Cab: Damp heat, steady state [20] }\end{array}$ \\
\hline
\end{tabular}

For the evaluation of chemical aging, the average molecular weight was determined by size exclusion chromatography (SEC) and by viscosity number $V N$ according ISO 307 [21]. The results of computed tomography (MicroCT) were used for analysis of the fiber orientation and the local fiber distribution. The determination of the tensile strength was carried out according to ISO 527-1 and ISO 527-2 with the ZWICK Z020 universal testing machine with a test speed of $50 \mathrm{~mm} / \mathrm{min}$ and for measuring of the Poisson's ratio the universal testing machine INSTRON 5507 was used [22,23]. For the latter one the tensile test was performed up to $90 \%$ of the yield stress at unreinforced PA6 material and in the case of PA6 GF material up to $90 \%$ of the value of the tensile strength at a test speed of $5 \mathrm{~mm} / \mathrm{min}$. In each case 5 test specimens for the determination of tensile strength and Poisson's ratio were used per tensile test. The change in the degree of crystallization was determined according to ISO 11537-1 by the measurement device METTLER-TOLEDO DSC 820 at a heating rate of $10 \mathrm{~K} / \mathrm{min}$ within a temperature range of $0-300{ }^{\circ} \mathrm{C}$ [24]. To assess the degree of crystallinity $K$, the value of $230 \mathrm{~J} / \mathrm{g}$ was selected for the enthalpy of fusion of 100\% crystalline PA 6 [25]. The orientation and local distribution of the glass fibers were analyzed by 3D X-ray MicroCT with the device GENERAL ELECTRIC NANOTOM M with a voxel size of 4 microns and subsequent software analysis with VOLUME GRAPHICS STUDIO MAX V2.2.

\section{Results and Discussion}

The tensile strength of glass fiber-reinforced PA6 GF materials depends to a small extent on the polymer matrix (composition of the macromolecules, the degree of crystallization, spherulite sizes, entanglement of molecular chains in the amorphous regions as well as additives) and to a large extent on the type of reinforcing glass fibers, with properties such as length and diameter, and the sizing. The fiber orientation distribution generated by the injection molding process has a further, special influence. The mold filling, with injection parameters like flow speed and progress, is influenced by the gate position and the gate profile. During the filling process a shear rate is formed in the polymer melt as a function of the flow conditions and flow processes. This shear rate can be derived from the thickness- and geometry-dependent profile of the flow rate. The shear rate results in a shear tension, which in turn is responsible for the orientation of the glass fibers [26-28]. The shear stress is lowest in the middle of the flow rate profile and therefore in this area the fiber orientation is transverse to the flow direction [26].

If the glass fiber orientation is analyzed by 3D X-ray MicroCT, as described above, for a defined region of a test specimen, the main components of the second stage tensor $\boldsymbol{T}_{\mathrm{FOD}}$ with $a_{x x}, a_{y y}$, and $a_{z z}$ can be calculated according Equation (1). The main tensor components represent the average distribution of glass fiber orientation and can be shown as a function of the thickness of the test specimen. This is shown in Figure 3 for three test specimens out of the position L1, L2 and L3 in the injection-molded plate. It is observable that in relation to the thickness of $4 \mathrm{~mm}$ the shear zone contains a high orientation of glass fibers in flow direction whereas in the core zone the glass fibers are transversely aligned. For a test specimen of position L1, most of the glass fibers are oriented in flow direction, represented by a high value of $a_{x x}$ up to 0.8 , except in the core area. For test specimen of position L2 and L3 the portion of oriented glass fibers in flow direction decreases, which is especially recognizable in the core area. This is supported by the investigations of McNally [29] and Toll and Anderson [30], which have found a transverse in-plane orientation of the glass fibers to the flow direction of injection molded plates in the core area. 


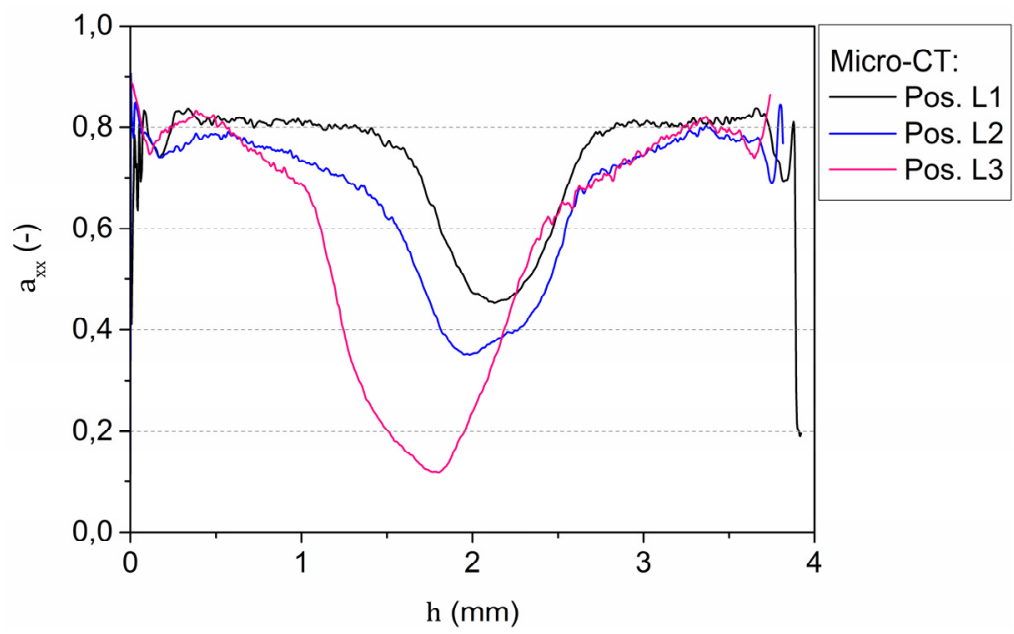

Figure 3. Difference of tensor component $a_{x x}$ as representation of glass fiber orientation in flow direction, analyzed by 3D X-ray MicroCT for the positions L1, L2 and L3 in the plate (see Figure 1).

The position-dependent glass fiber orientation influences mechanical properties like the tensile strength $\sigma_{\mathrm{M}}$ or the modulus of elasticity $E_{\mathrm{t}}$. In Figure 4 the stress-strain curves are shown for six positions (L1 to L6) of the injection molded plate for the material PA6 GF30 with $4 \mathrm{~mm}$ thickness. The symmetry of the mold filling due to the film gate can be seen in similar stress-strain curves of position L1 and L6, position L2 and L5 and position L3 and L4 (see Figure 2). By the filling, there are differences in the glass fiber orientation tensor within the molded plate, which cause a difference in the tensile strength of the longitudinally oriented specimens of around $23 \mathrm{MPa}$, corresponding to a relative difference of $9 \%$ of the mean value of $a_{x x}$. Furthermore, it is apparent that the elongation at break $\varepsilon_{\mathrm{tB}}$ of positions L3 and L4 from the center of the plate is more pronounced than the values from position L1, L2 or L5, L6.

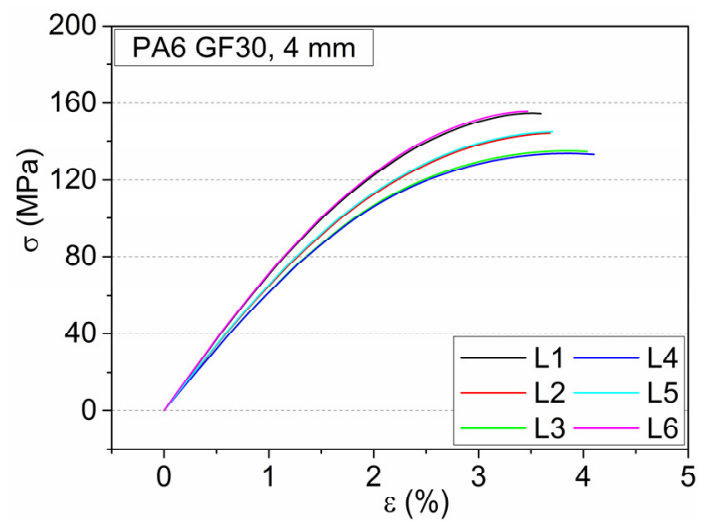

Figure 4. Stress-strain diagram of PA6 GF30 depending on the position in the injection molded plate.

The influence of glass fiber orientation as well as glass fiber content was mentioned by Kunz [11] and Saechtling [12]. In Figure 5, the Poisson's ratio for PA6 GF30 is shown depending on glass fiber orientation for different specimen thicknesses (Figure 5a), as well as glass fiber orientation for different glass fiber contents (Figure 5b). Furthermore, the linear fit curves for longitudinal and transverse orientation are implemented. 


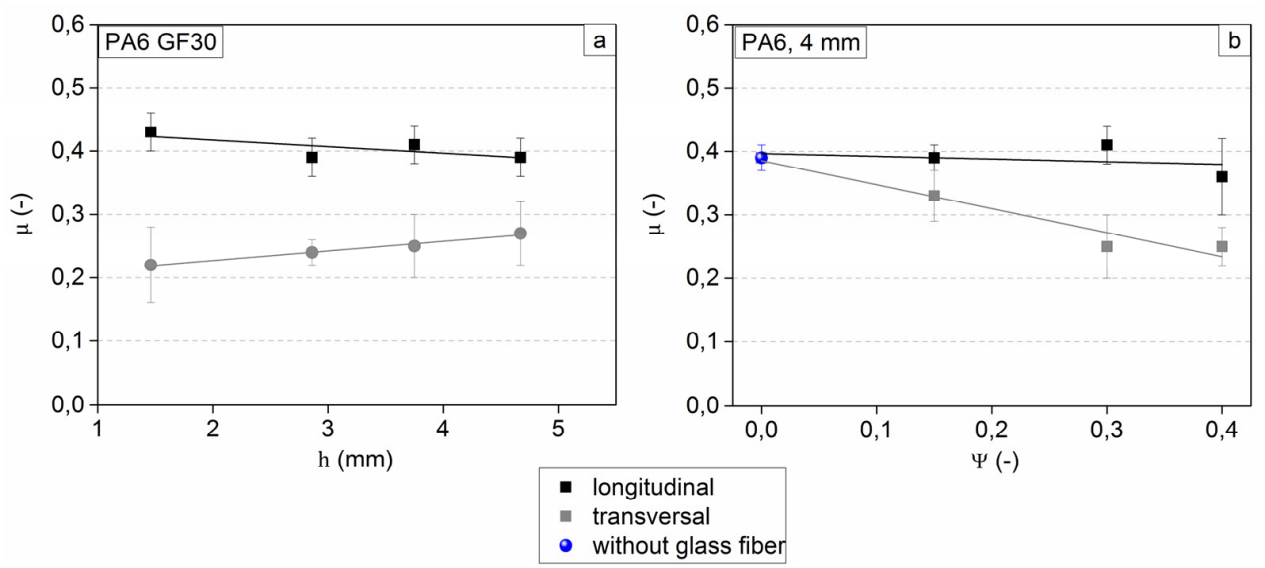

Figure 5. Poisson's ratio as a function of (a) specimen thickness with glass fiber orientation longitudinal and transverse; (b) glass fiber content at $4 \mathrm{~mm}$ thickness.

For the longitudinally oriented specimens with increasing thickness a decrease in the Poisson's ratio is characteristic (Figure 5a). The values lie in a range from 0.43 (at 1.5-mm thickness) to 0.39 (at 5 -mm thickness). For the transversely oriented specimens an increase in the Poisson's ratio from 0.22 (at 1.5-mm thickness) to 0.27 (at 5-mm thickness) can be observed. In Figure 5b, the Poisson's ratio for PA6 is shown at a constant sample thickness of $4 \mathrm{~mm}$, depending on the fiber orientation and the fiber content. Starting from a value of 0.4 for unreinforced PA6, in the longitudinal orientation a slight decrease is detectable with increasing glass fiber content. In comparison, with transverse orientation a greater decrease in Poisson's ratio is recognizable.

Due to the tendency of the Poisson's-ratio behavior in the longitudinal and transverse orientation shown in Figure 5, the Poisson's ratio as a function of the orientation tensor components $a_{x x}$ and $a_{y y}$, analyzed by MicroCT, is shown in Figure 6 . The values of the PA6 test specimen with $4 \mathrm{~mm}$ thickness and $30 \mathrm{wt} \%$ of glass fiber of the longitudinally oriented positions L1, L2 and L3 as well as the transversely oriented positions Q1 and Q3 were used. The same kinds of data sets were obtained for 1.5-mm and 3-mm thickness and are used in this diagram. In general, it could be observed that with increasing glass fiber orientation in the flow direction the Poisson's ratio increases, and that the range of values for Poisson's ratio $\mu$ depends on the orientation and lies in the range of 0.22 to 0.45 . A linear tendency of the dependency of Poisson's ratio on the glass fiber orientation is recognizable.

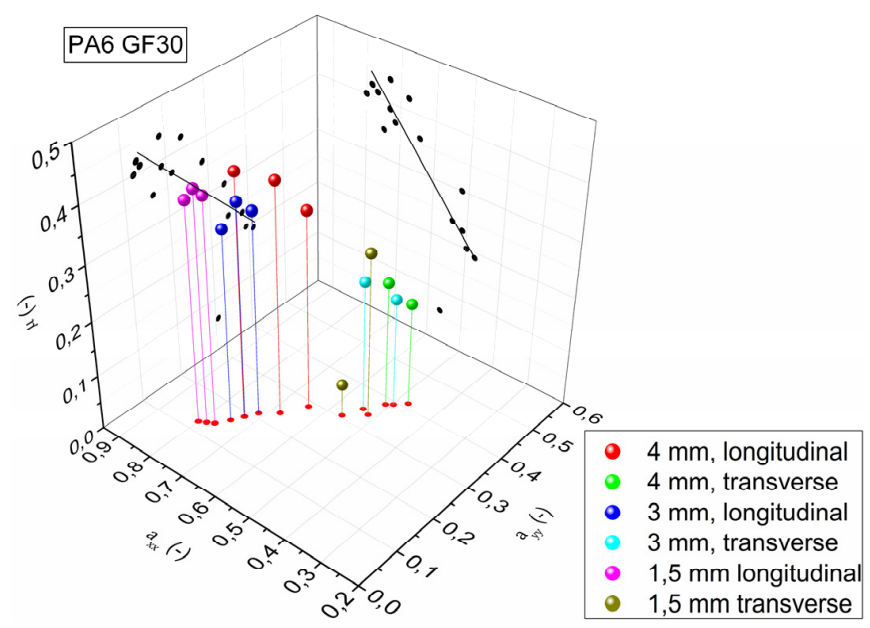

Figure 6. Poisson's ratio for PA6 GF materials with a thickness of $1.5 \mathrm{~mm}, 3 \mathrm{~mm}$ and $4 \mathrm{~mm}$ in longitudinal and transverse orientation direction as a function of the orientation tensor components $a_{x x}$ and $a_{y y}$; the linear tendency is shown as a black line. 
If the specimen PA6 GF materials are exposed to climate conditions at temperatures $>T_{\mathrm{g}}$ and at a high relative humidity, there will be different, parallel proceeding aging processes which influence one another. Firstly, an increase of mass occurs by absorption of moisture by the diffusion process, which is driven more by the concentration difference of the absolute amount of water between the environment and specimens than by the temperature [31,32]. Further, there is a post-crystallization, which is supported by the water absorption. The applied temperature and the absorbed moisture can each by itself, or in combination, cause a chemical aging process, such as chemical degradation, by chain branching or chain scission or hydrolysis. Exemplarily, in Table 3, change of degree of crystallization and moisture absorption, as well as change of viscosity number $V N$ and average molar mass, determined by SEC, are summarized for PA6 GF30 after $1000 \mathrm{~h}$ in high temperature and high humidity $\left(85^{\circ} \mathrm{C}, 85 \% \mathrm{RH}\right)$ in comparison to high temperature and low humidity $\left(85^{\circ} \mathrm{C}, 10 \% \mathrm{RH}\right)$.

Table 3. Summary of physical and chemical aging processes expressed as post-crystallization, moisture absorption, change of viscosity and molar mass after $1000 \mathrm{~h}$ for PA6 GF30.

\begin{tabular}{cccccc}
\hline No. & $\begin{array}{c}\text { Climate } \\
\text { conditions }\end{array}$ & Crystallization & $\begin{array}{c}\text { Moisture } \\
\text { absorption }\end{array}$ & $\begin{array}{c}\text { Viscosity } \\
\text { number }\end{array}$ & $\begin{array}{c}\text { Average } \\
\text { molar mass }\end{array}$ \\
\hline 1 & $85^{\circ} \mathrm{C}, 10 \% \mathrm{RH}$ & $+5.7 \%$ & $+0.1 \%$ & $+2.1 \%$ & $\pm 0 \%$ \\
2 & $85^{\circ} \mathrm{C}, 85 \% \mathrm{RH}$ & $+0.8 \%$ & $+3.1 \%$ & $-7.6 \%$ & $-8.2 \%$ \\
\hline
\end{tabular}

In climate storages of $1000 \mathrm{~h}$ with conditions of $85{ }^{\circ} \mathrm{C}$ and a relative humidity of $10 \%$ or $85 \%$ the Poisson's ratio changes as shown in Figure 7. The temporary progress of the Poisson's ratio is shown for two kinds of PA6 test specimen with a thickness of 1.5 and $4 \mathrm{~mm}$ with the same fiber content of $30 \mathrm{wt} \%$ for two independent climate conditions. Furthermore, the respective linear fit curves are shown. In dry climate storage only a slight decrease in Poisson's ratio is observed for both thicknesses, which is statistically not significant. The trend, which is observable, means a decrease from 0.43 to 0.39 for $1.5 \mathrm{~mm}$ thick specimen and from 0.41 to 0.38 for $4 \mathrm{~mm}$ thick specimen. This can be caused by a slight removal of water molecules inside the amorphous regions of the polymer matrix. It can also be supported by a post-crystallization process, which takes place under these climate conditions. In case of damp heat climate storage in $85^{\circ} \mathrm{C}$ and $85 \% \mathrm{RH}$, the Poisson's ratio increases at the beginning of the storage and shows afterwards a decreasing trend which is within the values of standard deviation.

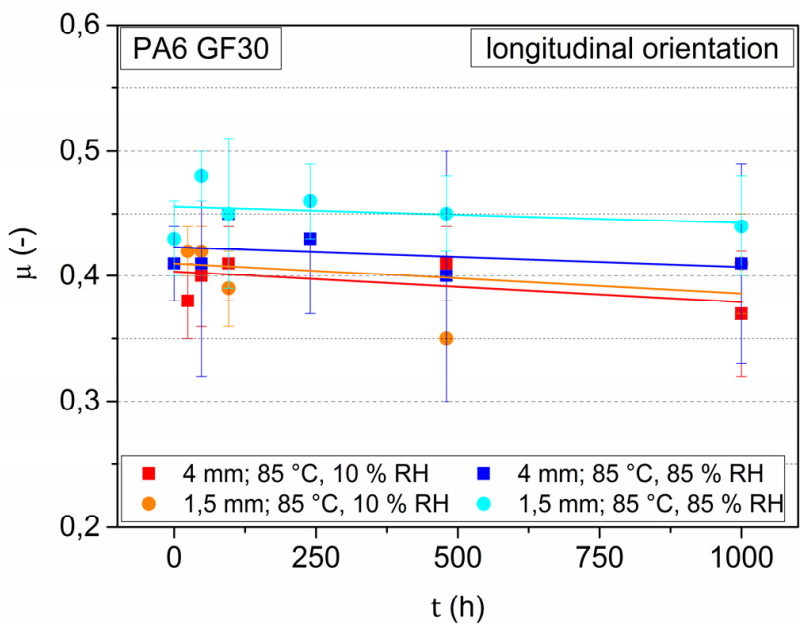

Figure 7. Change of Poisson's ratio $\mu$ during climate storage at $85{ }^{\circ} \mathrm{C}, 10 \% \mathrm{RH}$ and $85 \% \mathrm{RH}$ for PA6 GF30 with $1.5 \mathrm{~mm}$ as well as $4 \mathrm{~mm}$ test specimen thickness.

The comparison of the average change of Poisson's ratio $\mu$ after climate storage of $85{ }^{\circ} \mathrm{C}$ and $85 \%$ $\mathrm{RH}$ and constant glass fiber content as a function of sample thickness and glass fiber orientation is 
illustrated in Figure 8. In addition, the linear fit curves for longitudinal and transverse orientation are shown. In the longitudinal orientation a significant increase in the Poisson's ratio of about 0.02 over all test specimen thicknesses is recognizable. In transverse orientation on the other hand, a significant decrease in Poisson's ratio over all test specimen thicknesses of about 0.03 is observed. These effects are caused by the glass fiber content and by the moisture uptake, which weakens the polymer matrix. Given the weakened polymer matrix and in view of the ratio between test specimen thickness and width, the transverse strain $\varepsilon_{\mathrm{q}}$ increases more than the tensile strain $\varepsilon_{1}$ in longitudinally oriented test specimens. In transversely oriented test specimens the transverse strain $\varepsilon_{\mathrm{q}}$ increases less than the tensile strain $\varepsilon_{1}$ which leads to a decreasing Poisson's ratio [33].

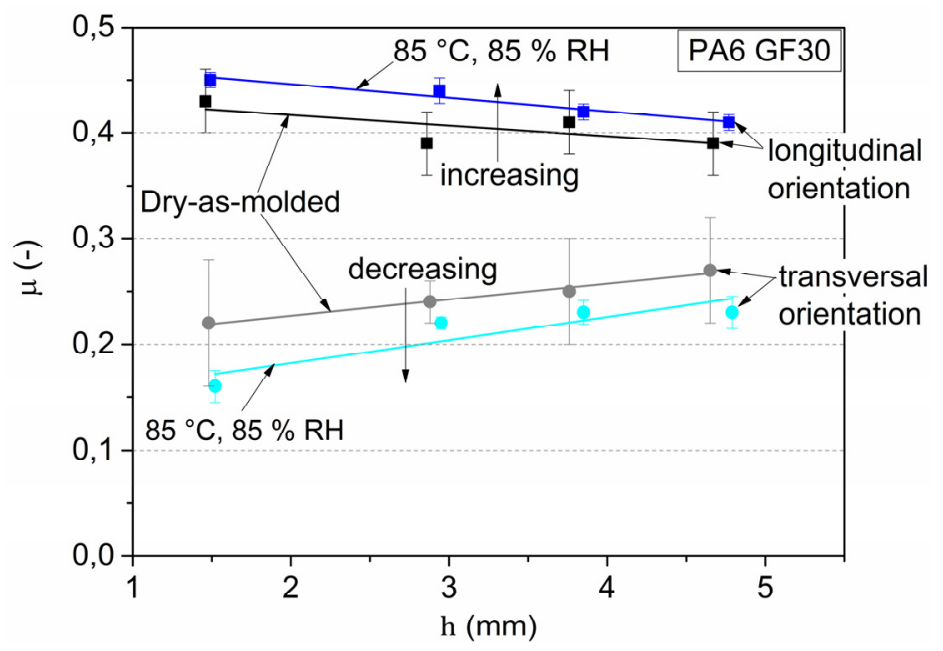

Figure 8. Change of Poisson's ratio depending on sample thickness, longitudinal and transverse orientation after climate storage of $1000 \mathrm{~h}$ in $85^{\circ} \mathrm{C}$ and $85 \% \mathrm{RH}$.

\section{Conclusions}

The Poisson's ratio is not only a constant value for glass fiber-reinforced PA6 materials, it depends on glass fiber content as stated before and additionally on glass fiber orientation. The Poisson's ratio decreases in the dry-as-molded state with increasing thickness and a glass fiber orientation mainly in flow direction. It slightly increases with a main glass fiber orientation transverse to the flow direction and increasing thickness of the test specimen. The values range from 0.22 to 0.43 and this difference can be correlated with the glass fiber orientation. The representation of the Poisson's ratio depending on the glass fiber orientation in the flow direction ( $a_{x x}$ as tensor component) shows a linear tendency. With hygrothermal aging, the Poisson's ratio changes depend on the climate conditions. In dry heat climate storage $\left(85^{\circ} \mathrm{C}, 10 \% \mathrm{RH}\right)$, only a slight decrease takes place, with thin and thick specimens tending to show the same behavior. In damp heat climate storage $\left(85^{\circ} \mathrm{C}, 85 \% \mathrm{RH}\right)$ the Poisson's ratio increases with longitudinal orientation in the same proportion as it decreases with transverse orientation.

Acknowledgments: The authors thank BASF SE, Ludwigshafen, for the provision of material and the implementation of the MicroCT. The authors also thank Polymer Service GmbH, Merseburg for the investigation of mechanical and thermal properties.

Author Contributions: Thomas Illing and Heinrich Gotzig conceived and designed the experiments; Marcus Schoßig and Thomas Illing performed the experiments and analyzed the data; Wolfgang Grellmann and Christian Bierögel contributed the analysis; Thomas Illing and Heinrich Gotzig wrote the paper.

Conflicts of Interest: The authors declare no conflict of interest. 


\section{References}

1. O'Gara, J.F.; Novak, G.E.; Wyzgoski, M.G. Predicting the tensile strength of short glass fiber reinforced injection molded plastics. In Proceedings of the 10th-Annual SPE ${ }^{\circledR}$ Automotive Composites Conference \& Exhibition (ACCE), Troy, MI, USA, 15-16 September 2010.

2. Thomason, J.L. Structure-property relationships in glass-reinforced polyamide, part 1: The effects of fiber content. Polym. Compos. 2006, 27, 552-562. [CrossRef]

3. Thomason, J. The influence of fibre properties of the performance of glass-fibre-reinforced polyamide 6,6 . Compos. Sci. Technol. 1999, 59, 2315-2328. [CrossRef]

4. Bernasconi, A.; Cosmi, F.; Dreossi, D. Local anisotropy analysis of injection moulded fibre reinforced polymer composites. Compos. Sci. Technol. 2008, 68, 2574-2581. [CrossRef]

5. Reinhart, C. Direkte CT-Datenanalyse mit VGStudio Max 2.0. In Industrielle Computertomografie Tagung 2008; Kastner, J., Ed.; Shaker Verlag: Aachen, Germany, 2008.

6. Bay, R.S.; Tucker, C.L. Fiber orientation in simple injection moldings. Part I: Theory and numerical methods. Polym. Compos. 1992, 13, 317-331. [CrossRef]

7. Bay, R.S.; Tucker, C.L. Fiber orientation in simple injection moldings. Part II: Experimental results. Polym. Compos. 1992, 13, 332-341. [CrossRef]

8. Advani, S.G.; Tucker, C.L. The use of tensors to describe and predict fiber orientation in short fiber composites. J. Rheol. 1987, 31. [CrossRef]

9. Domininghaus, H.; Elsner, P.; Eyerer, P.; Hirth, T. Domininghaus_Kunststoffe: Eigenschaften und Anwendungen; Springer Verlag: Heidelberg, Germany, 2008. (In German)

10. Hellerich, W.; Harsch, G.; Baur, E. Werkstoff-Führer Kunststoffe: Eigenschaften, Prüfungen, Kennwerte; Carl Hanser Verlag: München, Germany, 2010. (In German)

11. Kunz, J. Die Querkontraktionszahl in der Konstruktionspraxis. KunststoffXtra 2011, 6, 27-30. (In German)

12. Saechtling Kunststoff-Taschenbuch; Carl Hanser Verlag: München, Germany; Wien, Austria, 2001. (In German)

13. Bierögel, C.; Grellmann, W. Tensile loading. In Landolt-Börnstein, Mechanical and Thermomechanical Properties of Polymers; Grellmann, W., Seidler, S., Eds.; Springer Verlag: Berlin; Heidelberg, Germany, 2014; Volume VIII/6A3, pp. 136-142.

14. Rösler, J.; Harders, H.; Bäker, M. Mechanisches Verhalten der Werkstoffe; Springer Verlag: Wiesbaden, Germany, 2008.

15. Kohan, M.I. Nylon Plastics Handbook; Carl Hanser Verlag: Munich, Germany; Vienna, Austria; New York, NY, USA, 1995.

16. Becker, G.W.; Braun, D. Kunststoff-Handbuch. 3. Thermoplaste, 4. Polyamide; Carl Hanser Verlag: München, Germany; Wien, Austria, 1998; Volume 3.

17. BASF. Ultramid (PA) Product Brochure. BASF SE Ludwigshafen; BASF: Florham Park, NJ, USA, 2010.

18. Plastics-Multipurpose Test Specimens; ISO 3167; ISO Copyright Office: Geneva, Switzerland, 2014.

19. Environmental Testing-Part 2-2: Tests-Test B: Dry Heat; IEC 60068-2-2; IEC: Genevy, Switzerland, 2007.

20. Environmental Testing-Part 2-78: Tests-Test Cab: Damp Heat, Steady State; IEC 60068-2-78; IEC: Geneva, Switzerland, 2012.

21. Plastics—Polyamide—Determination of Viscosity Number; ISO 307; ISO Copyright Office: Geneva, Switzerland, 2007.

22. Plastics-Determination of Tensile Properties-Part 1: General Principles; ISO 527-1; ISO Copyright Office: Geneva, Switzerland, 2012.

23. Plastics-Determination of Tensile Properties-Part 2: Test Conditions for Moulding and Extrusion Plastics; ISO 527-2; ISO Copyright Office: Geneva, Switzerland, 2012.

24. Plastics_Differential Scanning Calorimetry (DSC)_Part 1: General Principles; ISO 11357-1; ISO Copyright Office: Geneva, Switzerland, 2009.

25. Ehrenstein, G.W.; Riedel, G.; Trawiel, P. Praxis der Thermischen Analyse von Kunststoffen; Carl Hanser Verlag: München, Germany, 2003. (In German)

26. Johannaber, F.; Michaeli, W. Handbuch Spritzgießen; Carl Hanser Verlag: München, Germany, 2004.

27. Laun, H. Orientation effects and rheology of short glass fiber-reinforced thermoplastics. Colloid Polym. Sci. 1984, 262, 257-269. [CrossRef]

28. Altan, M.C. A review of fiber-reinforced injection molding: Flow kinematics and particle orientation. J. Thermoplast. Compos. Mat. 1990, 3, 275-313. [CrossRef] 
29. McNally, D. Short fiber orientation and its effects on the properties of thermoplastic composite materials. Polym. Plast. Technol. Eng. 1977, 8, 101-154. [CrossRef]

30. Toll, S.; Andersson, P.O. Microstructure of long- and short-fiber reinforced injection molded polyamide. Polym. Compos. 1993, 14, 116-125. [CrossRef]

31. Vlasveld, D.; Groenewold, J.; Bersee, H.; Picken, S. Moisture absorption in polyamide-6 silicate nanocomposites and its influence on the mechanical properties. Polymer 2005, 46, 12567-12576. [CrossRef]

32. Low, H.; Liu, T.; Loh, W. Moisture sorption and permeation in polyamide 6/clay nanocomposite films. Polym. Int. 2004, 53, 1973-1978. [CrossRef]

33. Illing, T. Bewertung von Mechanischen und Thermischen Eigenschaften Glasfaserverstärkter Polyamid-Werkstoffe unter Besonderer Berücksichtigung des Alterungsverhaltens von Bauteilen in der Automobilindustrie; Martin-Luther-University Halle-Wittenberg: Merseburg, Germany, 2015. (In German)

(C) 2016 by the authors; licensee MDPI, Basel, Switzerland. This article is an open access article distributed under the terms and conditions of the Creative Commons Attribution (CC-BY) license (http://creativecommons.org/licenses/by/4.0/). 